\title{
Enhancing innovation performance of small and medium enterprises in Malaysia
}

\author{
Yee Yen Yuen ${ }^{a^{*}}$ and Xiang Ping Ng $^{\mathrm{a}}$
}

${ }^{a}$ Knowledge Management, Economics and Quantitative Analysis Department, Faculty of Business, Multimedia University, Malaysia

\begin{tabular}{l}
\hline C H R O N I C L E \\
\hline Article history: \\
Received: July 20, 2020 \\
Received in revised format: \\
September 102020 \\
Accepted: October 5, 2020 \\
Available online: \\
October 5, 2020 \\
\hline Keywords: \\
Innovation performance \\
R\&D collaboration \\
Quality Management \\
Small and Medium Enterprises \\
(SMEs)
\end{tabular}

\section{Introduction}

Global Innovation Index (GII) ranking of Malaysia emerged a decline from 32th dropped to 35th over the period of 20122019 based on the statistics of Malaysia Science and Technology Information Centre (MASTIC, 2020). This is a warning signal to Malaysia, which has remained an upper middle-income country since 1980s and government is aiming at achieving a high-income nation by 2020 (Rasiah \& Yap, 2015). This downturn and slow pace of Gross Domestic Product (GDP) growth since 1997 is mainly due to poor ratio of innovation performance of small and medium enterprises (SMEs) in the country (Aziz \& Samad, 2016). SMEs in Malaysia poor absorptive capacity to acquire new technological knowledge, which has resulted in a significantly lower level of innovation compared to their counterparts in other nations (Udriyah, Tham, \& Azam, 2019). A low level of innovative activities and a scarcity of innovative capabilities have affected the poor innovation performance (Fernando \& Wah, 2017). More than a quarter of SMEs in Malaysia (26\%) are still depending on non-local workers and half (49\%) of the employees in SMEs have an immediate need to improve innovative skills and abilities while establishment (Rasiah \& Yap, 2015). While high absorptive capacity is crucial for SMEs to enhance their innovation performance, absorptive capacity has been ignored due to high ambiguity (VanderWeele, 2016). SMEs will not be able to compete successfully with the world due to their low capabilities in accessing to management and technology, lack of skills for producing new product and poor adoptability to the current technology in acquiring and disseminating knowledge in the organization (Burhanuddin et al., 2009). Many SMEs in Malaysia think that technology is not necessary and add no value to their industries (Burhanuddin et al., 2009). Although Malaysia ranked $2^{\text {nd }}$ competitive country in ASEAN from Global Competitive Report 2017-2018 (MOSTIC, 2018), the level of R\&D and productivity are very low in SMEs in Malaysia (Zainal-Abidin et al., * Corresponding author.

E-mail address: yyyuen@mmu.edu.my (Y. Y. Yuen)

(C) 2021 by the authors; licensee Growing Science, Canada doi: $10.5267 /$ j.msl.2020.10.010 
2016). Only $0.5 \%$ of SMEs invested in R\&D even though most SMEs agree that internal R\&D collaboration increases innovation capability (Kratzer et al., 2005). Weak internal R\&D collaboration into effective innovation, poor innovative capability, limitation in R\&D lead to low level of innovation performance (Lichtenthale, 2016). One quarter or 44\% of employees in SMEs are either poor or very poor in sharing knowledge (Greene, 2019), more than $20 \%$ of them ignore the importance of knowledge sharing (Singh Sandhu et al., 2011). There are very little companies cultivate and implement knowledge sharing in SME Malaysia (Cerchione et al., 2016). Many relatively SMEs were limited by their ability to invest in innovation capabilities. As there is in deprive of a structured framework to guide SMEs in Malaysia on improving innovation performance, the objective of this study is to fill the gap by developing and validating a research model that includes key elements affecting innovation performance in Malaysian SMEs. Hence, the aim of present study is to contribute to a better understanding of innovation factors that affect innovation performance in SME in Malaysia. This study contributes to a better understanding of innovation factors that affect innovation performance.

This research provides managers in SMEs with better innovation strategies to achieve higher innovation performance. Moreover, policymakers can translate the research findings into policy implementation to help overcome the obstacles of sharing knowledge in organisation. This study contributes to the higher Global Innovation Index (GII) as when government has a clear understanding on SME's innovative problem in Malaysia, a clearer policy can be devised to help SMEs to improve their innovation performance.

\section{Literature review}

\subsection{Absorptive Capacity and Innovation Performance}

Amabalie (1996, p. 1) defines innovation as "the successful implementation of creative ideas within an organisation". Good innovation performance is important for SMEs to achieve and sustain competitive advantages (Tojeiro-Rivero, \& Moreno, 2019). Absorptive capacity refers to the degree to which a corporation can identify, adapt and extend new external knowledge to achieve higher level of innovation performance, as well as higher competitive advantage (Lichtenthaler, 2016). There is a positive connection between absorptive capacity and innovation, as that the company's innovation will improve when they have greater absorptive capacity (Mamun et al., 2017). Song et al. (2008) highlight a lack of strong relationship between absorptive capacity for innovation. Sáenz et al. (2014) demonstrated a positive relationship between absorptive capacity and capacity for innovation with no empirical statistical measure to verify the relationship. Therefore, this study therefore recommends the following hypothesis:

H1(a): Absorptive Capacity positively affects Innovation Performance.

\subsection{Technology Transfer and Performance of Innovation}

Sazali and Raduan (2011) viewed technology transfer as transfer of expertise between organ in order to produce a new product and to produce existing products more efficiently Technology transfer does not create significant attention in Malaysian firms (Jabar \& Soosay, 2010). Masri's (2013) shared similar finding that Malaysian SMEs are not emphasised in the overall business operation and innovation. This causes relatively low innovation capability and performance. There is a significant positive relationship between technology transfer and performance in innovation as well as innovation capabilities (Jabar \& Soosay, 2010)). According to Guan et al (2006), majority of the SMEs were relatively weak in technological innovation capability, which leads to poor innovation performance. Burhanuddin et al. (2009) also indicated that firms in developing countries such as Malaysia are lack of innovativeness and technology transfer. Taking into the consideration the importance of technology transfers in SMEs, the study suggests the following hypothesis:

\section{H1(b): Technology Transfer positively affects Innovation Performance.}

\subsection{Internal $R \& D$ Collaboration and Performance of Innovation}

Karabag and Berggren (2016) defines internal R\&D collaboration as the effort of SMEs in collaboratively work in an intellectual research and development endeavour to improve the innovation performance of the organization. Kaufmann (2001) describes internal R\&D collaboration as critical in helping firms to generate higher innovativeness level. Nadia (2014) discovers that an organisation is likely to achieve higher performance in innovation when it relies on higher internal R\&D collaboration. On the other hand, Hansen (2009) argued that the relationship between internal R\&D collaboration remains inconclusive. Beyerlein et al. (2003) found extensive internal R\&D collaboration might harm firms and suggested future researches to take note. In view of these inconsistent finding of this study, this research targets to examine internal R\&D collaboration relation to performance of innovation. Accordingly, this hypothesis proposed as below:

H1(c): Internal R\&D Collaboration positively affects Innovation Performance. 
Knowledge sharing is a behaviour of individuals to disseminate their knowledge to another colleague in the organisation (Bagherzadeh et al., 2019). Van den Hooff and Van Weenen (2004) define knowledge sharing as a process that an individual employee mutually exchanges knowledge and recreates new knowledge. The ultimate aims of knowledge sharing in SMEs is to make use of available expertise of employees in improving organisational innovation performance (Alavi \& Leidner, 1999). According to Lizarelli et al. (2019), organizational innovation will be attained when the existing organizational knowledge has been shared, adopted and utilised successfully in an organisation as a new idea, process, product or service. Nevertheless, according to Sulistiyani and Harwiki (2016), knowledge sharing is partially adopted in SMEs as a means to innovate. Yesil et al. (2013) even found no correlation between knowledge sharing and innovation performance. In order to confirm the impact of knowledge sharing on the innovation performance in Malaysian SMEs, Hence, the following hypothesis is tested in this study:

H1(d): Knowledge Sharing positively affects Innovation Performance.

\subsection{Innovation Capability and Innovation Performance}

This study introduces innovation capability as a new construct that affects innovation performance. Innovation capacity refers to the ability of a firm to mobilize the knowledge to create new knowledge for product and process innovations (Çakar \& Ertürk, 2010). Innovation capacity has been recognised to be a substantial driver for the success of entrepreneurial activity in SMEs (Paochoo, Ramayah \& Ahmad, 2014). However, sufficient evidence at firm level of innovation capacity to affect innovation performance is still lacking especially for developing countries like Malaysia (Chandran Govindaraju et al., 2013). This study, therefore, hypothesise that intellectual capacity could enhance innovation performance. Hence, the following hypothesis is developed and tested.

H4: Innovation Capability (Innovation Capability) positively affects Innovation Performance (Innovation Performance).

\begin{tabular}{|l|} 
Independent variables \\
\hline Absorptive Capacity \\
\hline Technology Transfer \\
\hline Internal R\&D Collaboration \\
\hline Innovation Capability
\end{tabular}

Fig. 1. Research framework

\section{Research methodology}

Out of 907,065 SMEs in Malaysia (SME Corporation Malaysia, 2019), this study selected three states with the highest number of SMEs, Selangor (19.8\%, 22497 SMEs), Wilayah Persekutuan Kuala Lumpur (14.7\%, 2154 SMEs), and Johor (10.8\%, 6257 SMEs). One hundred and fifty target respondents were selected from each of the three states equally, contributing to a total sample size of 450 respondents. The criteria of selecting the target respondents are the respondents must be at least serving at managerial level of the SMEs for more than 2 years to ensure that they have a good understanding of the company's innovation level to answer all questions in the questionnaire. The respondents were selected by using 2-stage cluster-sampling technique. At the first stage, three states with the highest number of SMEs in Malaysia were selected based on the listing provided by SME Corporation Malaysia (2020). Each state will have an equal number of respondents to be chosen randomly. Second, one hundred fifty respondents from the three chosen states were approached individually to administer the questionnaire. The researchers approach all target respondents face to face with paper questionnaire so that clarification could be provided when the respondents are in doubt with the questions. Four hundred fifty closed-ended survey forms were disseminated to respondents for reason that self-administered questionnaires have possibility of non-response. The survey form was disseminated personally to SMEs managerial level. From 450 survey form sent out, 386 questionnaires were returned (Response rate $=$ $85.78 \%$ ). After discarding questionnaires with incomplete responses, 300 valid questionnaires were used for analysis.

The results in Fig. 2 show that the most respondents are from SMEs in Kuala Lumpur, 117 participants (39\%), Selangor SMEs has $103(34.3 \%)$ respondents and Johor has the least number of 80 participants (26.7\%). Majority of the respondents are from well-established SMEs of 9 years and above (43.7\%). The respondents are high-ranking manager and director of the company with 5 to less than 75 employees and annual sales of RM300,000 to RM15 million. Half of the respondents in SMEs 135 (45\%) felt that innovation is extremely important towards the long-term success of a company. The greatest challenge of SMEs is to find ways to adapt to the quick evolution of innovation. The second challenge is hard to find and retain the best talent. This study used tolerance and variance inflation factor (VIF) to test multicollinearity using regression results. According to Hair et al. (2010), multicollinearity testing is one of the most important and reliable tests in analysis. The results in 
Table 1 show that there is no multicollinearity in this study because the tolerance ranges of all variables are within the acceptable range of 0.41 and 0.86 (higher than 0.1 ) and VIF range from 1.163 to 2.441, acceptable as less than 10 (Hair et al., 2010).

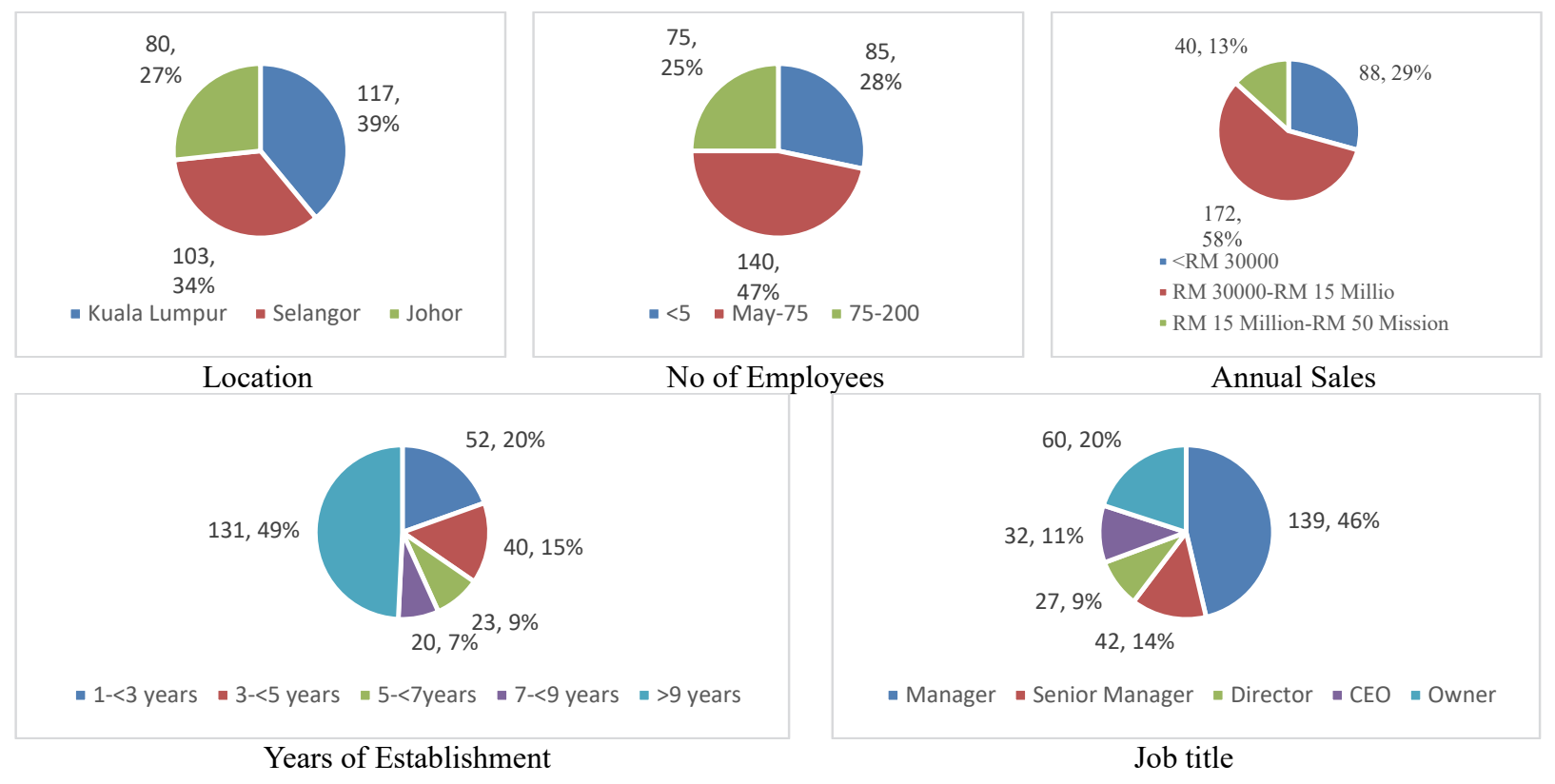

Fig. 2. Profile of the Respondents $(n=300)$

Table 1

Multicollinearity test

\begin{tabular}{ccc}
\hline Model & Tolerance & VIF \\
\hline Absorptive Capacity & .496 & 2.017 \\
Technology Transfer & .860 & 1.163 \\
Internal R\&D Collaboration & .563 & 1.777 \\
Knowledge Sharing & .852 & 1.173 \\
Innovation Capability & .410 & 2.441 \\
\hline
\end{tabular}

Dependent Variable: Innovation Performance

After analysing model's goodness of fit, this final model met the adequate index. The model statistics in Table 3 shows the improved fit with $\chi^{2} / \mathrm{df}=2.095, \mathrm{CFI}=0.912, \mathrm{TLI}=0.904$ and RMSEA $=0.061$ with the $\chi^{2}(\mathrm{df}=605, \mathrm{n}=300=1267.746$ and $\mathrm{p}=0.000$. According to Lai $(2015)$, it is normal that the model obtained significant value $(\mathrm{p}<0.001)$ as $\chi^{2}$ value is very sensitive to sample size. Therefore, these values indicate a good fit between model and observed data. According to Hair et al. (2010), measurement model provides factorial validity by mapping the multiple measured items onto the latent construct based on the theoretical justifications. It is crucial to evaluate the consistency and validity of the observable variables by assessing the composite reliability (CR), convergent validity by computing Average Variance Extracted (AVE), and discriminant validity (DV) which all constructs were correlated together in the model (Hair et al., 2010). The results show that all the constructs were adequate and achieved more than 0.7 of composite reliability. The highest CR value is Innovation Capability (0.935), Absorptive Capacity is second highest 0.928 and the lowest value is Internal R\&D Collaboration (0.749). Furthermore, all constructs achieve more than 0.5 for AVE, except Technology Transfer (0.439) and Internal R\&D Collaboration (0.432). Nevertheless, if the composite reliability exceeds 0.6 , the value of 0.4 is acceptable, the convergent validity of the constructs is acceptable (Safiih \& Azreen, 2016; Fornell \& David, 1981). Hence, AVE is achieved for every construct in the model. The results also indicate that all value of constructs is less than 0.85 for discriminant validity. This shows that the two exogenous constructs are neither redundant nor multicollinearity problem.

Table 2

Construct's Validity and Reliability

\begin{tabular}{cccccccc}
\hline Construct & CR & AVE & IC & AC & TT & RD & \\
\hline IC & 0.936 & 0.710 & $\mathbf{0 . 8 4 2}$ & & & & \\
AC & 0.926 & 0.642 & 0.732 & $\mathbf{0 . 8 0 1}$ & & \\
TT & 0.799 & 0.337 & 0.725 & 0.663 & $\mathbf{0 . 5 8 1}$ & \\
RD & 0.810 & 0.460 & 0.750 & 0.640 & 0.844 & $\mathbf{0 . 6 7 8}$ & 0.352 \\
KS & 0.918 & 0.691 & 0.373 & 0.360 & 0.332 & 0.572 & 0.594 \\
PIP & 0.919 & 0.532 & 0.614 & 0.580 & 0.531 & \\
\hline
\end{tabular}

$\mathrm{CR}=$ Composite Reliability; AVE= Average Variance Extracted; the diagonal elements (in bold) are the square roots of AVEs (Source: SEM Output) 


\section{Hypothesis testing result}

H1a: Absorptive capacity and Innovation performance have a significant relationship.

The finding in Table 3 indicates that absorptive capacity affects innovation performance. The result shows $\beta=0.401$ and $\mathrm{p}<0.001$, significant at 0.05 level, suggesting absorptive capacity had a significant positive relationship with innovation performance. The construct absorptive capacity causes the companies to learn new knowledge affected companies, or influence them to more efficient on innovation. The significant value is less than 0.05 , meaning that absorptive capacity could predict innovation performance. Therefore, H1a is supported. The study addressed that absorptive capacity is an important variable. Absorptive capacity is critical because it promotes company in learning new knowledge, to acquire more skills on improving development, integrating old and new knowledge in the company as well as is the key for businesses to achieve higher innovation performance (Lagunes et al., 2016). Absorptive capacity is important as it focuses on the internal processes that learned from the past (Schilling \& Shankar, 2019). The overall results showed that absorptive capacity is one of the factors affect innovation performance.

H1b: Technology Transfer and Innovation Performance have a significant relationship.

The analysis result shows that the technology transfer does not significantly affect innovation performance at $\beta=0.045$ and $\mathrm{p}=0.44$ in Table 3 . This shows technology transfer has no significant relationship with innovation performance as $\mathrm{p}$ value is not at significant level $(\mathrm{p}>0.05)$. The results represent that technology transfer such as upgrading machines equipment or upgrading product line could not motivate, relate with innovation performance in SME. The findings are in line with previous studies, a majority of surveyed firms is relatively weak in technology transfer. Hence, very few technology transfer constructs were significant relationship towards innovation performance (Guan et al., 2019). In the study of Liu et al. (2019) also revealed technology transfer has no significant relationship with innovation performance. Hence, H1b is not supported. Technology transfer is not a significant variable in the study. Transferring skills within the company does not directly impact on innovation. This result is consistent with previous studies (Guan et al., 2019) and suggest that technology transfer did not relate to innovation performance in developing countries. The research on technology management by Eldred and McGrath (1997) revealed that that there is no guarantee that technology transfer would result in successful innovation or produce adequate return on investment. Hence, it will not be effective if the recipient is not able to utilise, reproduce and improve the skills or knowledge for innovation.

\section{H1c: Internal R\&D Collaboration and Innovation Performance (Innovation Performance)have a significant relationship.}

The result demonstrates a significant hypothesis testing at $\beta=0.327$ and $p<0.001$. The results suggest that there is a significant relationship between internal R\&D collaboration and innovation performance. Companies took part in product development to improve innovation performance explained by the results. The result implies that Malaysian SMEs, which focus on research and development, achieve higher innovation performance. Thus, H1c is supported. Furthermore, internal R\&D collaboration suggests as a significant effect on innovation performance, allowing a company to achieve and maintain its competitive advantage (Kim et al., 2011). Internal R\&D collaboration leads to introduce new products, commercializing products, sales from innovation (Hottenrott \& Lopes-Bento, 2016).

\section{H1d: Knowledge sharing and innovation performance have a significant relationship.}

Knowledge sharing affects innovation performance. This result is significant at $\beta=0.146$ and $p=0.01$. Knowledge sharing and innovation performance have a significant relationship. This indicated that sharing information among colleagues or employees influence on innovation performance, the more they share, the higher innovation performance is achieved. Thus, H1d is supported. This finding is consistent with Hanif and Asgher (2018)'s results, which show that appropriately utilizing knowledge will provide benefits of innovation for a firm is strongly related. Knowledge sharing will be utilised when members sharing task-relevant ideas, information, and suggestions with each other (Tohidinia \& Mosakhani, 2010). Knowledge is one of a company's most vital assets in an organisation and a variable to stimulate the process of innovation (Yesil et al., 2013; Zeraati et al., 2019). The respondents also show that knowledge sharing is crucial and strongly linked to innovation from the survey in the study.

Table 3

Hypothesis Testing Result

\begin{tabular}{|c|c|c|c|c|c|c|}
\hline Hypothesis & Structural Path & $\boldsymbol{b}$ & SE & $\boldsymbol{\beta}$ & c.r. & $p$ \\
\hline H1a & Absorptive Capacity $\rightarrow$ Innovation Performance & 0.384 & 0.059 & 0.401 & 6.48 & $<0.001$ \\
\hline $\mathrm{H} 1 \mathrm{~b}$ & Technology Transfer $\rightarrow$ Innovation Performance & 0.12 & 0.156 & 0.045 & 0.772 & 0.44 \\
\hline H1c & Internal R\&D Collaboration $\rightarrow$ Innovation Performance & 0.223 & 0.043 & 0.327 & 5.179 & $<0.001$ \\
\hline H1d & Knowledge Sharing $\rightarrow$ Innovation Performance & 0.135 & 0.052 & 0.146 & 2.584 & 0.01 \\
\hline
\end{tabular}




\section{Managerial implication}

On practical side, the research provides some contributions. First, it was found that most of the SMEs in Malaysia do not focus much in innovation. Thus, this research may provide a way for them to follow. The first implication can be contributed is managerial support. Many top managements scare to change and have a tendency to "wait-and-see" (Pattinson and Chen, 2019), prior to implementing new practices or changes into their organisations. So, the findings of this study are useful to those traditional SMEs.

Since the findings imply that innovation factors will enhance the level of innovation performance, top management able to take it as a reference to re-organize or more focus on innovative activities. Some management policies or regulations should support innovation activities. For instance, those policies that oppose or make it difficult to create innovation activities need to be restructured or taken into account so that SMEs have greater opportunities to contribute to innovative capacity and performance. Understanding the factor of SMEs low in innovation is essential in anchoring future direction for innovation in firm. The findings show that an absorptive capacity of company requires more new knowledge than just focus on existing knowledge.

In the light of this, the study gives an insight to management to have an idea on how to improve employees' abilities, such as to provide training, improve knowledge, how to integrating new and old knowledge as well as collaboration. The findings also allow stakeholders to understand the importance of developing or upgrading line and what factors caused their business in low innovation performance. In such, in order to upgrading development, stakeholder and management should have innovation strategic planning continuously. SMEs in Malaysia need to keep increasing human capital and ability to ensure that they have adequate resource to overcome and manage innovation activities. The findings of this study allow SMEs in Malaysia to have an idea be more innovative than larger enterprise because of SMEs' innovation performances are yet to reach full potentials at the present moment.

In addition, top management should be more innovative and support on R\&D collaboration in innovation. Such example in doing development, involving in consultancy or partnership with R\&D agency, which can achieve higher innovation performance. Top management knows what elements and requirements needed for developing a product. The study provides a blueprint for top management what makes knowledge sharing initiatives so important to effect in innovation as well. This study also contributes to manufacturing SMEs in a term of what factors make the industry to step back from innovation, what is necessary to proactive in order to make innovation happen.

On the other hand, since Malaysian government is moving into K-based economy, this research provides guidelines to understand the factor, which result SMEs in low innovation performance. GDP of SMEs in Malaysia to overall economic remain relatively small compared to their counterparts in advanced countries (47.2\%) and other high middle income countries (SME Corporation Malaysia, 2019); thus, this also provide policy makers in ensuring appropriate approaches in public agencies and governmental departments. The findings lead a way for government to adopt a measure to improve SMEs in innovativeness level. This is in line with the Malaysia SMEs master plan (2012 to 2020) (SME Corporation Malaysia, 2019), that within 6 high impact programmes (HIP) of the SME master plan, this study would contribute to 2 of the HIP. The first is technology platform where to promote innovative idea, in a simple word to promote innovation activities in a commercialization stage. This can stimulate SME to develop more and more innovative idea and upgrade from a traditional business concept. Secondly, inclusive innovation which to empowering the bottom $40 \%$ of income group to leverage on innovation through the transformation of rural community through hand-holding approach (SME Corporation Malaysia, 2019). Hence, this research helps government to have a better approach on how to transform rural community, such as providing more training and development to improve innovative capability, R\&D collaboration to SME and technology support since SME in manufacturing sector has grown at a slower pace in 2016.

\section{Theoretical implication}

This study has remarkable theoretical implications. First, the study has succeeded in developing an adapted framework to examine innovation factors and innovation performance that can engage in fieldwork. The framework is made up of four main variables that can predict to influence innovation performance in SME Malaysia. Furthermore, the research also contributed to the knowledge base by providing better insight into innovation in SMEs. Most of the studies only considered examined innovation factors in other contexts (e.g.: Kumar \& Rose, 2012; Cyril Eze et al., 2013; Ismail et al., 2013; Sulistiyani \& Harwiki, 2016; Eze et al., 2013), where insufficient to provide a holistic and comprehensive evidence towards innovation performance. Thus, by adapting absorptive capacity as one of the factors of innovation factors shed the light on how company acquires or learns new knowledge, integrating old and new knowledge to support on innovation level. Technology transfer is also an element of assessing innovation performance. However, it does not highly paid attention by most of the SMEs due to lack of financial and skill labours. Although some previous studies show has engaged with innovation performance, this study shows no relationship due to the company not fully understand the process and importance. Apart from the technology transfer contributed in this study, internal R\&D collaboration is a major contributor to good innovation performance. SMEs should 
focus more on research and development activities so that able to improve higher innovativeness level. The last variable contributed to research is knowledge sharing. Improvement comes from knowledge and without sharing. Knowledge sharing flow within firm enables create a more innovative idea to achieve higher innovation performance.

\section{Recommendations}

There are some recommendations for managers and government. First, top management should find out the main root of low innovation performance in company before implementing new planning. Despite of government support, innovation in SMEs still at low level. From this point of view, the firms' top management executives are advised to focus on innovation activities to ensure effective implementation. However, top management must support manager to make the activities happen. Innovation initiatives would be more aggressive if top management involves directly. The current study suggests top management to upgrade employee's knowledge and skills by providing more training consistently and integrating with existing knowledge. As such, management are recommended to have better strategic planning to support innovation activities. In addition, the government should provide more support to local SMEs since the challenges faced by SMEs are the low-level technology transfer, lack of skilled human capital, poorly developed industrial and lack of R\&D as well as operating in isolation from the world centres of innovation. Government should provide tax exemption to crucial R\&D initiative of SMEs to reduce financial burden and improve innovativeness level. Government should also educate SMEs on using more technology in order to keep pace with the times and innovate a new and timely demanded product to meet a market requirement. Although the government has supported SMEs, it shows government still have room to bring more education and subsidy to local business so that SME able to improve innovation level as SME is the economy backbone in Malaysia. Moreover, as most of the Malaysian SMEs are local business or family business with practicing traditional business concept. From the observation, it is important to upgrade their poorly developed industrial and technological infrastructure. Government needs to promote the importance of innovation will affect the business. SMEs can be more innovative through learning, knowledge sharing and upgrading skills. Improving innovation performance is a stage-by-stage approach institutionalised across a whole firm. The government or community needs to understand the different perspective between rural and urban SMEs before implementing new policy or education, such as the capability level and innovativeness level.

\section{References}

Abd Aziz, N. N., \& Samad, S. (2016). Innovation and competitive advantage: Moderating effects of firm age in foods manufacturing SMEs in Malaysia. Procedia Economics and Finance, 35(2016), 256-266.

Alavi, M., \& Leidner, D. (1999). Knowledge management systems: issues, challenges, and benefits. Communications of the Association for Information Systems, 1(1), 7.

Burhanuddin, M. A., Arif, F., Azizah, V., \& Prabuwono, A. S. (2009, April). Barriers and challenges for technology transfer in Malaysian small and medium industries. In 2009 International Conference on Information Management and Engineering (pp. 258-261). IEEE.

Çakar, N. D., \& Ertürk, A. (2010). Comparing innovation capability of small and medium-sized enterprises: examining the effects of organizational culture and empowerment. Journal of Small Business Management, 48(3), 325-359.

Chandran Govindaraju, V. G. R., Krishnan Vijayaraghavan, G., \& Pandiyan, V. (2013). Product and process innovation in Malaysian manufacturing: The role of government, organizational innovation and exports. Innovation, 15(1), 52-68.

Eldred, E. W., \& McGrath, M. E. (1997). Commercializing new technology-II. Research-Technology Management, 40(2), 29-33.

Fernando, Y., \& Wah, W. X. (2017). The impact of eco-innovation drivers on environmental performance: Empirical results from the green technology sector in Malaysia. Sustainable Production and Consumption, 12(1), 27-43.

Fornell, C., \& Larcker, D. F. (1981). Structural equation models with unobservable variables and measurement error: Algebra and statistics.

Guan, H., Zhang, Z., Zhao, A., Jia, J., \& Guan, S. (2019). Research on innovation behavior and performance of new generation entrepreneur based on grounded theory. Sustainability, 11(10), 2883.

Hanif, M. I., \& Asgher, M. U. (2018). Service innovation and service innovation performance: A study of banking services. Pakistan Journal of Commerce and Social Sciences (PJCSS), 12(2), 670-694.

Hottenrott, H., \& Lopes-Bento, C. (2016). R\&D partnerships and innovation performance: Can there be too much of a good thing?. Journal of Product Innovation Management, 33(6), 773-794.

Kim, S. K., Lee, B. G., Park, B. S., \& Oh, K. S. (2011). The effect of R\&D, technology commercialization capabilities and innovation performance. Technological and Economic Development of Economy, 17(4), 563-578.

Lagunes, P., Soto, A., Zuñiga, S., \& Pérez, J. C. (2016). Model for Determining the Absorption Capacity of SMES in the Manufacturing Sector. European Scientific Journal, ESJ, 12(34).

Liu, Y., Kim, J., \& Yoo, J. (2019). Intangible Resources and Internationalization for the Innovation Performance of Chinese High-Tech Firms. Journal of Open Innovation: Technology, Market, and Complexity, 5(3), 52.

Lizarelli, F. L., Toledo, J. C. D., \& Alliprandini, D. H. (2019). Relationship between continuous improvement and innovation performance: an empirical study in Brazilian manufacturing companies. Total Quality Management \& Business Excellence, $31(2020), 1-24$ 
Malaysia Science and Technology Information Centre [MASTIC]. (2020). Global Innovation Index. https://mastic.mestecc.gov.my/statistic/international-ranking/global-innovation-index

Paochoo, Rapeepan, T. Ramayah, and Noor Hazlina Ahmad. The effects of innovation capabilities and sufficiency economy philosophy on internationalization performance among entrepreneurial SMEs in Thailand. International SME Conference (ISMEC 2014), 18 to 19 August 2014, Kuala Lumpur 136-148.

Pattinson, J. A., \& Chen, H. (2020). A barrier to innovation: Europe's ad-hoc cross-border framework for testing prototype autonomous vehicles. International Review of Law, Computers \& Technology, 34(1), 108-122.

Rasiah, R., \& Yap, X. S. (2015). Innovation performance of the Malaysian economy. The Global Innovation Index $2015,139$.

Safiih, L. M., \& Azreen, N. (2016). Confirmatory factor analysis approach: A case study of mathematics students' achievement in times. Malaysian Journal of Mathematical Sciences, 10, 41-51.

Schilling, M. A., \& Shankar, R. (2019). Strategic management of technological innovation. McGraw-Hill Education.

SME Corporation Malaysia. (2019). SME Definitions. Retrieved from: https://smecorp.gov.my/index.php/en/policies/202002-11-08-01-24/sme-definition [2020, February 11]

Sulistiyani, R., \& Harwiki, W. (2016). How SMEs build innovation capability based on knowledge sharing behavior? Phenomenological Approach. Procedia-Social and Behavioral Sciences, 219(1), 741-747.

Tohidinia, Z., \& Mosakhani, M. (2010). Knowledge sharing behaviour and its predictors. Industrial Management \& Data Systems.

Udriyah, U., Tham, J., \& Azam, S. (2019). The effects of market orientation and innovation on competitive advantage and business performance of textile SMEs. Management Science Letters, 9(9), 1419-1428.

VanderWeele, T. J. (2016). Mediation analysis: a practitioner's guide. Annual Review of Public Health, 37(1), 17-32.

Yeşil, S., Büyükbeşe, T., \& Koska, A. (2013). Exploring the link between knowledge sharing enablers, innovation capability and innovation performance. International Journal of Innovation Management, 17(4), 1350018.

Zeraati, H., Rajabion, L., Molavi, H., \& Navimipour, N. J. (2019). A model for examining the effect of knowledge sharing and new IT-based technologies on the success of the supply chain management systems. Kybernetes, 49(2), $229-251$.

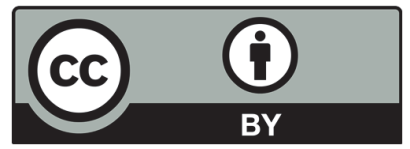

(C) 2020 by the authors; licensee Growing Science, Canada. This is an open access article distributed under the terms and conditions of the Creative Commons Attribution (CC-BY) license (http://creativecommons.org/licenses/by/4.0/). 